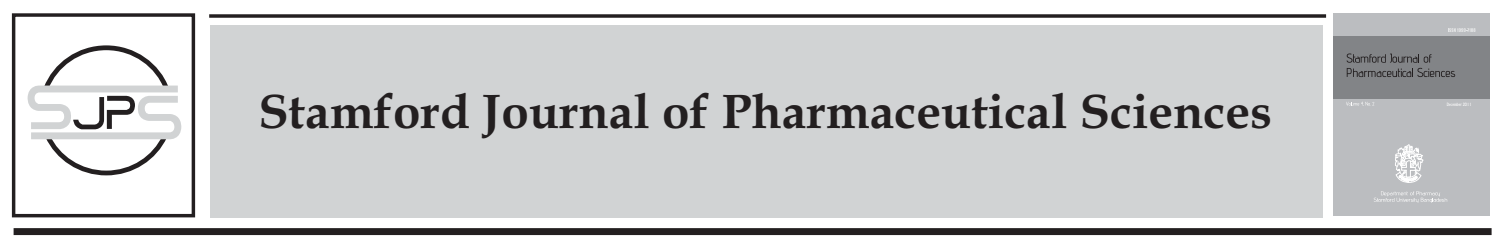

\title{
Practice of using gifts as promotional materials for marketing of pharmaceutical products in Bangladesh: A survey conducted on general physicians and representatives from pharmaceutical companies
}

\author{
*Saki Sultana1, Kamrul Hasan Khosru² \\ ${ }^{1}$ Department of Pharmacy, BRAC University, Dhaka-1212, Bangladesh \\ ${ }^{2}$ Kamrul Hasan Khosru, Officer, Research and Development, Beximco Pharmaceuticals Ltd., Tongi, Gazipur
}

Original Research Article

\begin{abstract}
The present study was undertaken to find out the promotional strategies followed by the pharmaceutical companies, attitudes and responses of physicians towards these promotional activities and influence of using gifts as promotional materials on the prescribing behavior of the physicians. In the study we found that most pharmaceutical companies believe that pharmaceuticals should be promoted by their quality and availability, not by any other promotional strategies. $84.62 \%$ pharmaceutical companies believe that gifts provided by them motivate the physicians to prescribe their products whereas $87 \%$ physicians admit that they consider the image of the company and quality of the product while prescribing. We also found that $50.5 \%$ physicians preferred information more rather than attractive gifts but only $11.77 \%$ pharmaceutical companies agreed with this statement.
\end{abstract}

Keywords: pharmaceutical marketing, promotion, physicians, gifts, strategies.

\section{INTRODUCTION}

There are several sectors on which Bangladesh can be proud of and undoubtedly the pharmaceutical sector is one of them. At present, there are 262 Allopathic drug manufacturing companies in Bangladesh (Directorate General of Drugs Administration, 2011). According to Bangladesh Pharmaceuticals and Healthcare Report Q1 2011, Bangladesh medicine sales reached taka 7,000 crore in 2010. Business Monitor International in its latest report (Q1 2011) said Bangladesh has moved up one place to occupy the 14th position in 17 regional markets surveyed in BMls Pharmaceutical \&

*Corresponding Author:

Saki Sultana

Lecturer, Department of Pharmacy, BRAC University

66, Mohakhali, Dhaka-1212, Bangladesh

Phone: 880-2-8824051-4, Ext: 4060, Fax: 880-2-8810383

E-mail: sultanasaki@gmail.com
Healthcare Business Environment Ratings for the Asia region (BD drugs.com, 2011). More than $95 \%$ of the total national requirement of medicines is fulfilled by the local pharmaceutical companies and the rest is imported (Islam, 2008). At present drugs are exported to around 83 countries. In 2010 Bangladesh exported about formulated medicines of about 3813.50 million taka (Directorate General of Drugs Administration, 2011). The annual average growth rate of this sector was $16.80 \%$ in 2009 (Chowdhury, 2010) and Bangladesh's pharmaceutical industry contributes almost $1 \%$ of GDP. It is the third largest tax paying industry in the country. According to IMS, a US-based market research firm, the retail market size is around BDT 55 billion (Chowdhury, 2010). About $80 \%$ of the drugs manufactured by the local companies in Bangladesh are generics and $20 \%$ are patented drugs. We 
Table 1: Comparative study of the preference of gift items by physicians and pharmaceutical companies.

\begin{tabular}{lccccc}
\hline \multicolumn{1}{c}{ Type of gifts } & Physicians & Companies & $\begin{array}{c}\text { Percentage of } \\
\text { physicians (\%) }\end{array}$ & $\begin{array}{c}\text { Percentage of } \\
\text { companies (\%) }\end{array}$ & $\begin{array}{c}\text { Deviation } \\
(\%)\end{array}$ \\
\hline Desk item & 58 & 9 & 29 & 52.94 & 23.94 \\
$\begin{array}{l}\text { Household \& personal } \\
\begin{array}{l}\text { Patient care leaflet or } \\
\text { informational }\end{array}\end{array}$ & 41 & 6 & 20.5 & 35.29 & 14.79 \\
\hline Total & 101 & 2 & 50.5 & 11.77 & 38.73 \\
\hline
\end{tabular}

manufacture about 450 generic drugs for 5,300 registered brands having 8,300 different forms of dosages and strengths. It is a matter of pride that Bangladesh is the top generic medicine producer among the 48 least developed countries in the world, with a $70.9 \%$ share in terms of total sales (WHO, 2004). Although we have made a substantial progress in drug manufacturing but there are some factors that are affecting the total health care system badly of our country. Irrational use of drugs, inappropriate prescribing, inadequate access to essential drugs, and uncontrolled price of medicines are among some of those major problems (Islam, 2006).

The local pharmaceutical market of Bangladesh is increasing day by day. Its promotional budget is booming due to bullfight competition and no market segregation among too many companies. Now-a-days pharmaceutical promotion attracts the attention of the people due to ambiguous and irrational prescriptions of pharmaceuticals by many physicians. Unethical marketing of drugs is quite common in Bangladesh. Major unethical practices observed in our pharmaceutical marketing include off-label promotion of drugs, delivery of misinformation about the product, evasion of contraindications, exaggeration of efficacy, and underestimating the adverse effects (Chowdhury et al. 2006, Islam, 2008). Actually, there has been no proper drug use study in the country (Chowdhury, 2005). Indiscriminate uses of clinically inappropriate and inefficient medicines are a serious problem here. More than $50 \%$ of the medicines in Bangladesh are inappropriately prescribed, dispensed or sold (Chowdhury et al, 2006). It has become a big question whether the physicians are influenced by the promotion by pharmaceutical companies or not. In this study we wanted to find out the behavior of the physicians towards the gifts that they receive from the pharmaceutical companies and the behavior and strategy of the pharmaceutical companies to promote their products. Specifically the study was conducted to find out the promotional strategy in Bangladesh pharmaceutical market. The study was also focused to understand whether the gifts played a vital role in promotional strategy or gifts could motivate physicians in their prescribing behavior.

\section{MATERIALS AND METHODS}

The focus of this study was physicians' attitudes surrounding the 'gift relationship' between pharmaceutical companies and physicians. Randomly selected 17 pharmaceutical companies of Bangladesh and 200 practicing physicians of Dhaka, Sylhet and Rangamati comprised the study population. Designations of the contact persons of the pharmaceutical companies were assistant manager or senior product executive or product executive. The study was conducted from August 2009 to February 2010.

To get the best knowledge on the purpose of the study, the survey method was taken as the better way to communicate with the pharmaceutical companies and physicians than any other option. As the physicians and the contact persons of pharmaceutical companies were unwilling to disclose their identity, it was not disclosed. 


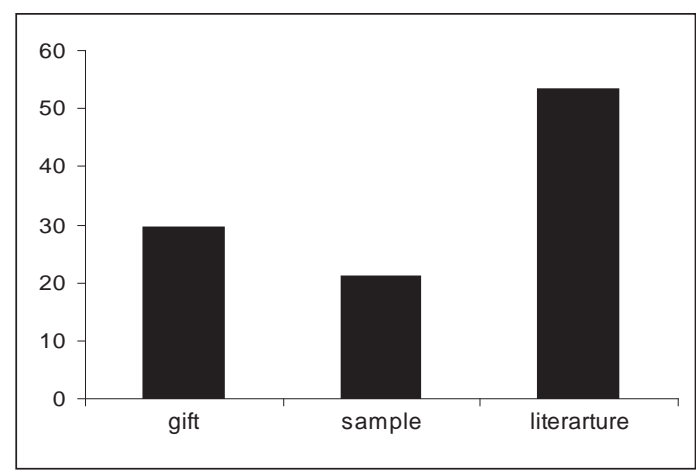

Figure 1: Physicians' preference for promotional materials.

The survey instruments used in this study were two separate questionnaires for physicians and pharmaceutical companies. Physicians were given some multiple choice questions and requested to write down the probable answers that they liked most that helped them to prescribe a product. A same type but separate questionnaire was given to each company under study. Based on the responses received from the physicians and pharmaceutical companies, no changes were deemed necessary in the final questionnaire. All data input, format, transformation and analyses were performed using Microsoft Excel®.

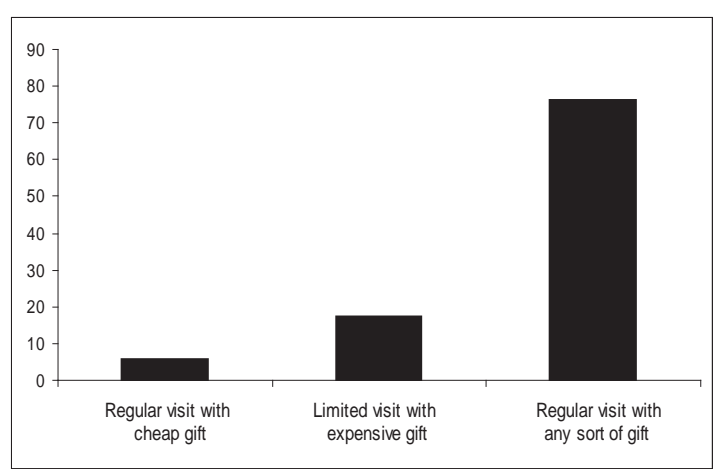

Figure 2: Physicians' preference towards frequency and type of receiving gifts.

\section{RESULTS AND DISCUSSION}

In our survey, it was found that most of the physicians (53.5\%) preferred literature, $29.5 \%$ preferred gifts and the rest $21 \%$ preferred sample as promotional materials (Figure 1).

As our intention was to find out the motivation of prescribing attitude of the physicians by the gift items, we asked them about the type of gifts that they liked most to receive from the companies. $47 \%$ of them answered for patient care leaflets, $32 \%$ for desk items and the rest $21 \%$ for household gifts. This result indicated that most of the physicians preferred information and desk items from the pharmaceutical companies rather than household items. $85 \%$ physicians thought that

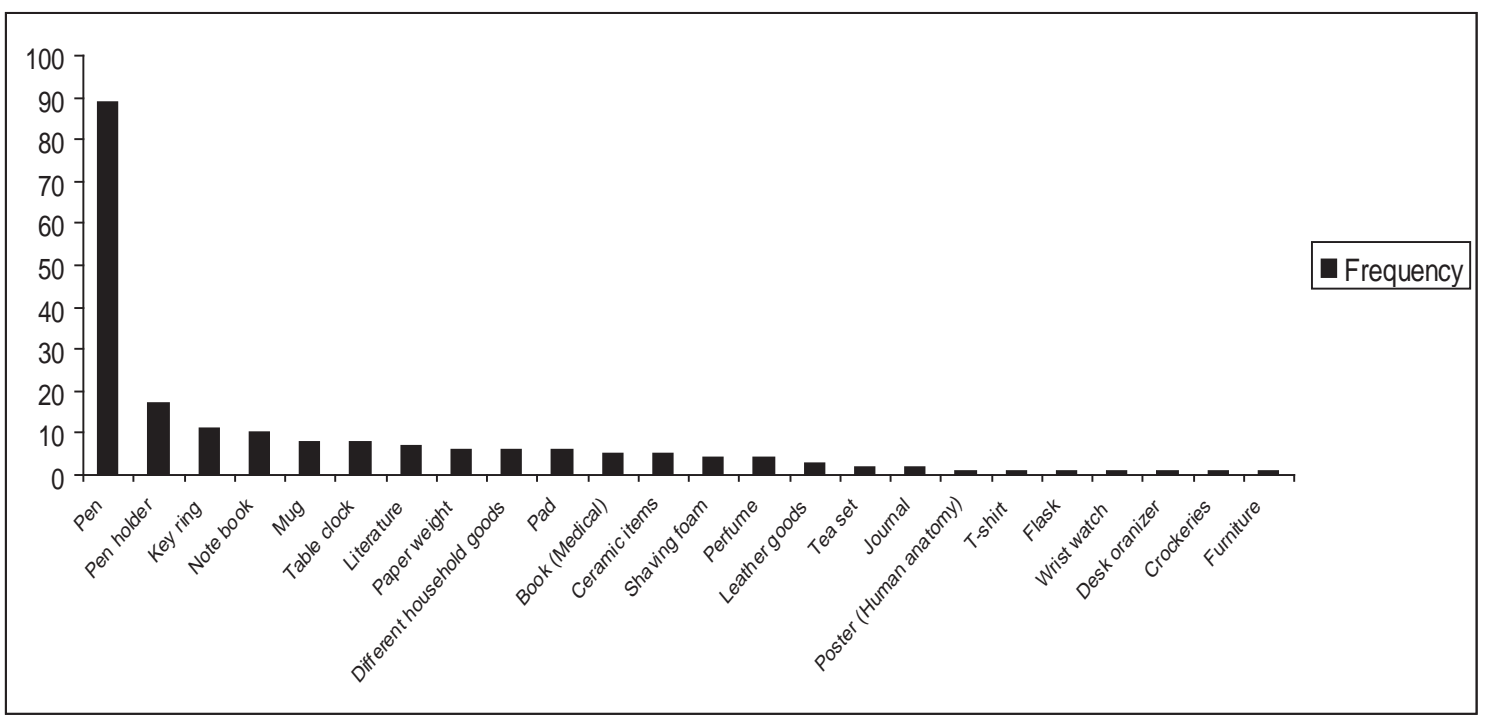

Figure 3: Physicians' preference for gift items. 


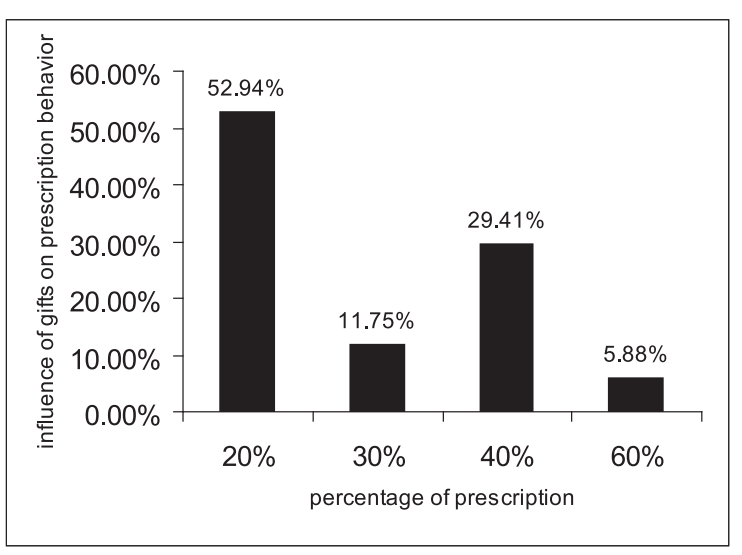

Figure 4: Percentage of the prescriptions influenced by the gift items.

gifts were helpful to remember the brand name. $78 \%$ physicians told that they were satisfied with the type and quality of gifts provided by the pharmaceutical companies. $88.5 \%$ physician supported indication oriented gifts because these helped them to remember the positioning of the brand. When the physicians were asked about their preferable way and frequency of receiving gifts, most of them did not like regular visits of pharmaceutical company representatives (PCR) with cheap gifts. It was annoying to them. Another interesting result was that physicians also did not like limited visits with expensive gifts.
Most of them (76\%) liked regular visits with any sort of gift, $17.5 \%$ preferred limited visits with expensive gifts and only $6 \%$ preferred regular visits with cheap gifts (Figure 2).

This result indicated that they liked to be remembered or to be updated with information by the company. Physicians were aware of the quality of the pharmaceuticals. $87 \%$ of them admitted that they considered image of the company and quality of the product while prescribing and $13 \%$ told that they were motivated by the costly gifts provided by the company. $70 \%$ of them continued prescribing the pharmaceutical products even if the company had terminated the promotion (gift) of the product .We asked physicians to write down the name of the gifts that they preferred most and thus we found a long list. The most common and preferable gift items are shown in figure 3.

In order to get the information about the gift items that the pharmaceutical companies offer to physicians as promotional materials, we also had a survey on the companies' attitude, thoughts and strategy about such promotions.

In our study we found that $82.4 \%$ pharmaceutical companies thought pharmaceutical marketing different from the conventional one. $52.9 \%$ companies believed

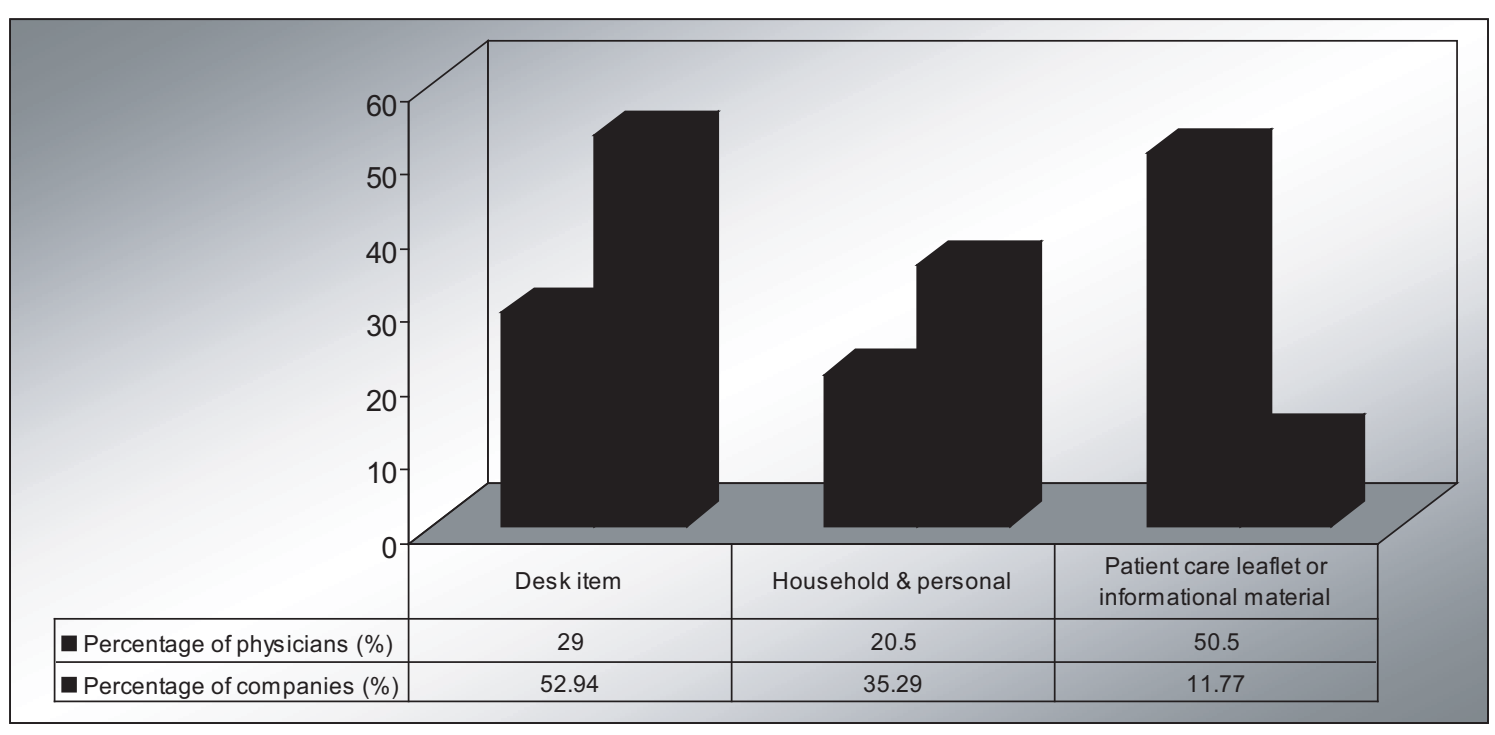

Figure 5: Attitude of physicians' \& pharmaceutical companies towards gift items. 


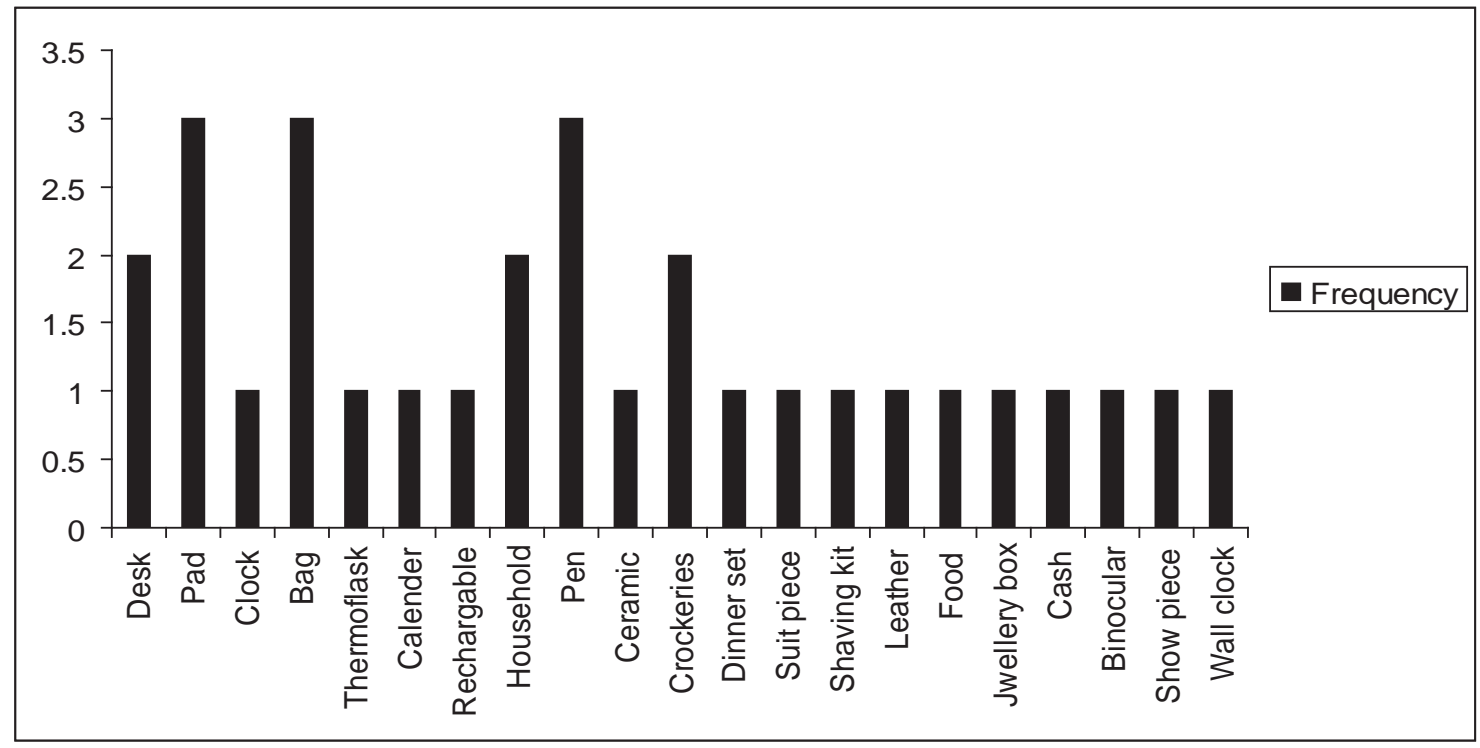

Figure 6: Preference of pharmaceutical companies for gift items.

that ideally pharmaceuticals should be promoted by their quality and availability, not by any other promotional strategy. Only $11.7 \%$ companies thought that promotional strategy should be followed maintaining high quality of the product and making it available for the patients. According to $76.5 \%$ companies, it was beneficial economically for the company to follow their own promotional strategy. $58.8 \%$ companies told that promotional costs did not increase the maximum retail price of their products. $52.94 \%$ of the pharmaceutical companies thought that the promotion of pharmaceuticals depended on promotional materials. None followed the strategy of only one gift or sample or literature. It may be due to failure of the single material strategy in promotion. $46.15 \%$ companies preferred the use of sample with literature for promotion. The rest $(53.85 \%)$ preferred gifts with sample $(23.08 \%)$ or gifts with literature $(30.77 \%)$. Most (84.62\%) pharmaceutical companies believed that gifts could motivate physicians to prescribe a product. They also thought that costly gifts were more motivational and $70.59 \%$ pharmaceutical companies supported this statement. This anomaly became clear when the question was about prescription behavior of physicians. 52.94\% companies thought that only $20 \%$ prescription behavior could be influenced by gifts and $29.41 \%$ companies believed that $40 \%$ prescription behavior of physicians were influenced by gift items (Figure 4).

Most of the pharmaceutical companies thought that desk items might be more fruitful in promotion because physicians spent huge time in their desk and thus $52.94 \%$ pharmaceutical companies preferred desk items. Informational items were not popular $(11.77 \%)$ to the companies. It may be due to failure of such items to attract the attention of physicians to the brand. The rest (35.29\%) liked household \& personal use gift items (Table 1, Figure 5). So it was clear that companies evaluate physicians' attention towards attractive gifts before selecting gift items. It is also observed from Table 1 and Figure 5 that physicians emphasized more on information (50.5\%) and then on desk items (29\%).

We asked persons from different companies to write down the name of some gift items that they found popular to the physicians. By this way a big list was found. Among them pen, pad, desk organizers, bag, crockeries were some most common ones (Figure 6). 


\section{CONCLUSION}

Pharmaceutical is one of the highest priority sectors in Bangladesh. Among the 49 Least Developed Countries (LDCs), Bangladesh has the strongest base to manufacture pharmaceutical products (Jahan, 2011). We have a large population and so have a large market. As pharmaceuticals are prohibited to promote to the mass, and a patient follows the prescription prescribed by the physician, pharmaceutical companies try to motivate the physicians in many ways.

We tried to make a good and honest survey on our derived topic. But there might be some anomalies in information obtained from the pharmaceutical companies and the physicians, as there was a requirement of some confidential records or information for the study and the persons might be unwilling to disclose such information. The anomalies could be minimized if all parties under study provided real information regarding those confidential questions. Thus the limitation of the study could be minimized.

The geographical area used in this study was limited. So generalization of the results is restricted for all physicians in Bangladesh. The study included only 17 pharmaceutical companies of our country and due to our limitations we could not reach most other pharmaceutical companies.

However from the study report the overall promotional scenario of the pharmaceutical marketing of Bangladesh and the prescription behavior of the physicians can be guessed.

\section{REFERENCES}

Bangladesh Association of Pharmaceutical Industries (BAPI). Available at: http://www.bapibd.com. [Accessed on: May 20, 2011]. BD drugs.com. Available at: http://bddrugs.com/detail.php?nid=13 [Accessed on: October 01, 2011].

Chowdhury AKA (2008). Bangladesh core group report. INRUD; International Network for Rational Use of Drugs News. 15(1): 7-8.

Chowdhury FR, Rahman MM, Ahasan HAMN (2006). National Drug Policy of Bangladesh: some pitfalls in implementation. J Coll Physicians Surg Pak. 16 (5): 36870. PMid:16756785

Chowdhury FR, Rahman MM, Huq MF, Begum S (2006). Rationality of drug uses: its Bangladeshi perspectives. Mymensingh Med J. 15(2): 215-9. PMid:16878109

Chowdhury PM. (2010) An overview of the pharmaceutical sector in Bangladesh. Available at: http://www.eplbangladesh.com/brokerage/research/1301 468109Pharma_Overview.pdf [Accessed on: October 01, 2011]

Directorate General of Drugs Administration (DGDA), Bangladesh. Available at:

http://www.dgda.gov.bd/index.php?menuName=Allopathi c\&mmn=Manufacturers [Accessed on: April 29, 2011].

Islam MS (2006). A Review on the Policy and Practices of Therapeutic Drug Uses in Bangladesh. Calicut Medical Journal. 2nd Ed. 4 (4).

Islam MS (2008). Off-label promotion of drugs in Bangladesh: evidence from promotional brochures circulated among general practitioners by pharmaceutical companies. International journal of pharmacy practice. 16: 409-412. http://dx.doi.org/10.1211/ijpp.16.6.0011

Islam MS (2008). Therapeutic drug use in Bangladesh: policy versus practice. Indian Journal of Medical Ethics. $5(1): 24-25$.

Jahan S (2011) UK Trade \& Investment Sector briefing: Pharmaceutical Opportunities in Bangladesh. Available at:

http://static.globaltrade.net/files/pdf/20110926121243121. pdf [Accessed on: April 29, 2011]

World Health Organization (2004). The world medicines situation. Geneva: World Health Organization. 